\title{
Interpretation of Insecticide Posters by Rice Farmers In Selected Villages in Leyte, Philippines
}

\author{
Dennis C. Cortes ${ }^{1}$ and Monina Escalada ${ }^{2}$ \\ ${ }^{1}$ TV 5 Media Center, Reliance St. Cor. Sheridan St., Mandaluyong, Metro Manila, \\ Philippines, ${ }^{2}$ Department of Development Communication, Visayas State \\ University, Baybay City, Leyte 6521-A
}

\section{ABSTRACT}

Farmers usually get pesticide information from different sources, such as radio, television, print ads, extension technicians, pesticide sales agents, other farmers, and their own experience. This study focused on rice farmers' interpretation of insecticide use in outdoor print advertisements in selected rice growing provinces in Leyte, Philippines. One hundred farmers were individually presented with six insecticide posters and asked to give their feedback. A focus group discussion was also conducted to obtain more insights into the participants' assessment of the poster's ability to grab attention, their understanding of the message, perceived acceptability, and self-involvement. Packaging (insecticide bottle), images that connote power and strength such as boxing gloves, superman and the peso sign, slogan, color, and brand name were found to be attractive elements of the posters. Most respondents understood the message conveyed by nearly all posters. Only a few respondents found something offensive and untrue in the text and slogans used. Overall results of the study proved that insecticide posters were effective in encouraging unnecessary insecticide use. Focus group discussion results indicated that farmers had knowledge gaps and misconceptions of the posters' message. For instance, they misconstrued that the posters encouraged them to use more insecticides when that recommendation was not in the posters. It appears that pesticide use has been well entrenched in the minds of farmers that a poster appears to be a trigger for insecticide use.

Keywords: Interpretation, pest management practices, insecticide posters, users' feedback

\section{INTRODUCTION}

Insecticides, which represented $56 \%$ of the total pesticide trade in 1996, are the most used type of pesticide in the Philippines. The largest gross amount of pesticides in the Philippines is used in rice because of its large production area (Greenpeace, 2008). Pesticide use in rice areas has become a common scenario in farming although most rice farmers may not understand the ways and reasons for using it. Farmers often lack adequate knowledge about pest control and their pesticide use is sometimes not rational (Rola and Pingali, 1993). Thus, many integrated pest management (IPM) programs have focused on changing rice

Correspondence: Monina Escalada Address: Department of Development Communication, Visayas State University, Baybay City, Leyte 6521-A E-mail: m.escalada@gmail.com

DOI: $10.32945 /$ atr3811.2016 
farmers' pest management and rationalizing pesticide use (Escalada et al., 2009).

IPM advocates strongly believed that overuse of chemical pesticides can seriously damage the ecosystem and the environment (Mangan and Mangan, 1998). They also noted that natural pest control in farming has also reduced due to a reliance on chemical control. Pesticides often bring pest outbreaks by killing beneficial insects (FAO, 2000). Moreover, the excessive use of pesticide can generate new pest species which are highly resistant and invulnerable to pesticides (Mangan and Mangan, 1998).

The overuse of insecticides in rice described as "pesticide tsunami" by Cheng and Heong (2010) has altered farmers' sustainable practices in farming. Pesticide companies operate in the rural areas, making pesticides readily available to farmers. Remote areas which can hardly be visited by extension agents rely on pesticide "kiosks" operated by different pesticide companies. Most of these kiosks become default pest control advisers (Cheng and Heong, 2010).

IPM initiatives have used the mass media to improve farmers' pest management decisions in pesticide use. Print materials, such as pamphlets and posters, billboards, and radio and TV programs were specifically designed to motivate farmers to reduce unnecessary insecticide use (Escalada, Heong, Huan and Mai, 1999).

Aggressive advertising and marketing campaigns launched by the pesticide industry have made a significant impact on pesticide use (Cheng and Heong, 2010). Kincheloe and Horn's study (2006) noted that modern-day advertising generally uses conditioning to create associations between products and consumer needs. Knowing that these kinds of connection are usually temporary, companies follow Pavlov's ideas of repetition and continually advertise to keep these associations in farmers' minds (Escalada et al., 2009).

Farmers usually get pesticide information from different sources. In China, farmers learned about pesticide use from government technicians, pesticide sales people, pesticide labels, and other farmers (Li, Guo, Hu, and Liang, 1997). Moreover, Diaz (2002) noted that farmers in the Philippines just rely on their field experience and follow the trial and error method in using agrochemical inputs. Mass media ads in radio, television, and print are also some of the information sources of pesticide information among rice farmers in Thailand (Upanisakorn, 1997).

Lichtenberg and Zimmerman (1999) indicated that farmers regard first-hand sources of information such as direct field observation and pesticide labels as being the most important. Thus, processing of information on pesticide advertising needs to be systematically assessed.

\section{RESEARCH METHODS}

\section{Research Design, Setting and Respondents}

The study followed the one-shot survey research design. Farmers were selected through random sampling in each study site. Only barangays in large ricegrowing areas, as identified by agricultural technicians during an informal interview, were selected. Moreover, these sites were also accessible to the researcher. A slight modification was made of the sample sizes in each barangay 
due to the unavailability of respondents at the time of the interview (see Table 1).This study was conducted in rice growing areas in Leyte particularly in Albuera, Hilongos, Baybay, and Ormoc City.

Table 1. Distribution of respondents in study areas.

\begin{tabular}{llc}
\hline \multicolumn{1}{c}{ Municipality } & \multicolumn{1}{c}{ Barangay } & Sample Size \\
\hline Ormoc & Licuma & 20 \\
Albuera & Planas & 30 \\
Baybay & Hibunawan & 30 \\
Hilongos & Concepcion & 20 \\
\hline \multicolumn{2}{c}{ Total } & 100 \\
\hline
\end{tabular}

Selection of the Stimulus Materials

Stimulus materials. In Leyte, more than 20 pesticide posters are usually displayed in the community. Six samples of rice insecticide posters distributed and displayed inside and outside the agrochemical supply stores were selected by the pesticide sales technicians. These were posters on Applaud (buprofezin), Lorsban (chlorpyrifos), Legend (esfenvalerate), Chix (betacypermetrin), Nurelle (chlorpyrifos), and Anvil (sumithrin) which were shown to the respondents in an arranged exposure. Farmers were gathered in a barangay hall and were requested to examine the pesticide posters which were presented at random manner to control primacy and recency effects. Each poster was presented for three minutes. After viewing each poster, respondents were interviewed to gather data on the dependent variable measures.

\section{Data Gathering Tools and Procedure}

Individual interviews. Farmers were gathered in a barangay hall to collect their background information through a questionnaire. With the help of senior year development communication students who were trained in interviewing, respondents were asked first about their background characteristics and pest management practices. Next, respondents were exposed to the first poster for three minutes. After the exposure, respondents were asked about their interpretation of the poster. The same procedure was followed until the last poster was viewed. The poster number corresponds to these insecticide products: 1 Applaud, 2 - Lorsban, 3 - Legend, 4 - Chix, 5 - Nurelle, and 6 - Anvil.

Focus group discussion. Participants in the FGD consisted of 10 farmers. Questions dealing with respondents' perceptions and reactions to pesticide information in the insecticide posters were raised in the discussion.

\section{RESULTS AND DISCUSSION}

Respondent Profile

Of the 100 farmers interviewed, 59\% were men and $41 \%$ were women (Fig. 2). Almost half of the respondents (35\%) fell in the 46-60 age bracket, followed by 32 percent who belonged to the 22-45 years old age group. More than one-fourth (28\%) were 61-76 years old and the remaining five percent were in the 21 years old 
age group. In terms of education, $50 \%$ attended elementary level of education and $26 \%$ had reached high school level. Some $11 \%$ reached the college level and $13 \%$ had no schooling at all. Most had spent their lives as rice farmers, with farming experience ranging from 5-60 years and averaging 25 years. Farmers had an average rice yield of $2 \mathrm{tha}^{-1}$.

Interpretation of Posters

To examine respondents' interpretation of the posters, Bertrand's (1978) measures of effectiveness were applied, namely, attractiveness, comprehensibility, acceptability and self-involvement.

Attention. To gauge the attention of the respondents to each poster, they were asked which part grabbed their attention the most and why. Figure 1, which summarizes the responses across the six posters, shows that packaging or the insecticide bottle and images used in the label drew the attention of two-thirds of the respondents $(67 \%)$. Respondents specified that images of strength, i.e., boxing gloves, Superman, and the peso sign, were attractive. Slogan (43\%), poster text $(36 \%)$, and brand name $(13 \%)$ were other elements specified by respondents. When respondents were asked why the poster grabbed their attention, most of them indicated that the poster used words that were catchy or pleasant to hear or they found it to be pleasing, realistic, and attractive.

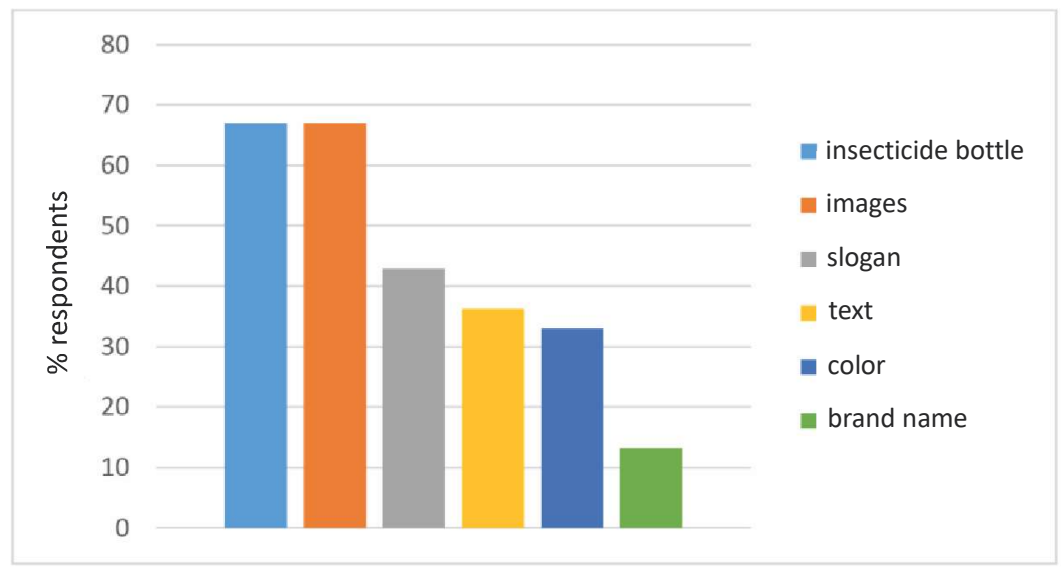

Fig. 1. Poster elements which grabbed respondents' attention.

Comprehensibility. Comprehensibility refers to the extent to which the respondents understood the content of the posters. Respondents were also asked for the message of the poster, the slogan, and the text. Their responses to these three questions were then scored if correct, incorrect, or don't know. The sum of correct scores for each poster was then aggregated into three levels: low (0-6 points), moderate (7-13 points), and high (14-20 points). Figure 2 reveals that the majority of respondents gave the correct message of the poster and their correct answers fell in the high category. 


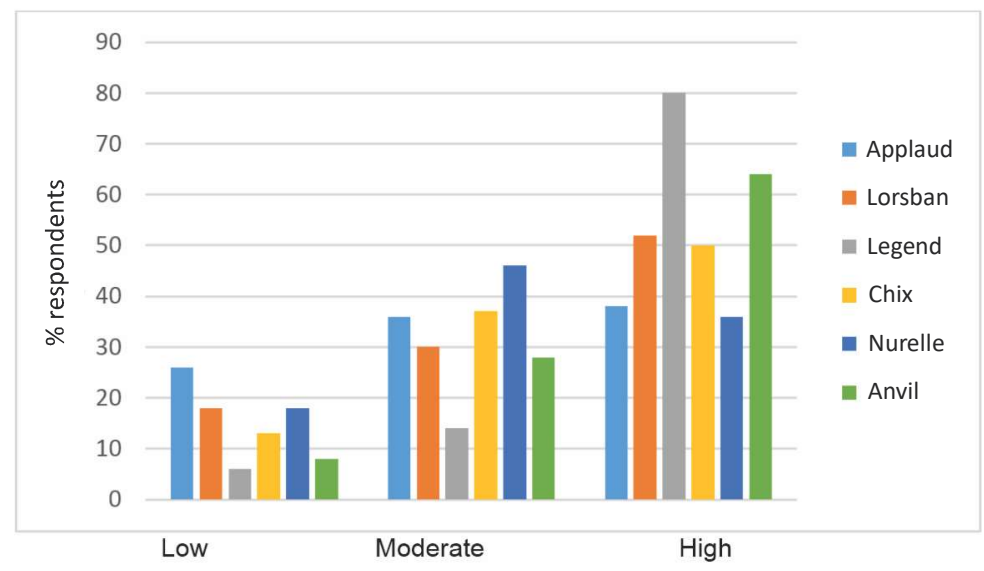

Fig 2. Perceived comprehensibity of posters.

Acceptability. Respondents were asked if there was something in the poster that they found to be offensive (Fig. 3) and they did not believe to be true (Fig. 4). Results show that the big majority of the respondents did not find anything offensive in the posters nor did they find content that they did not regard to be true. The small percentage of respondents who found something offensive mentioned the words, "caution", "150\%", and "super triple". Poster images considered not to be true were: Superman, boxer's arm, dense rice hills, quality rice and sword, and the letter X, and slogans such as "Super at grinding hoppers" and "Wipe out hoppers and borers".

Self-involvement. Across the six posters, exactly four-fifths of the respondents thought that farmers like them were the intended audience of the posters while about $10 \%$ each of the respondents expressed that these were meant for hired spray laborers or the general public (Table 2). The reasons given by respondents for thinking that the poster was either meant for them or for hired sprayers are presented in Table 2 .

Table 2. Self-involvement of posters.

\begin{tabular}{lccrrrr}
\hline & \multicolumn{5}{c}{ Posters } \\
\cline { 2 - 6 } Self-involvement & 1 & 2 & 3 & 4 & 5 & \multicolumn{1}{c}{6} \\
\hline $\begin{array}{l}\text { Intended audience } \\
\quad \text { Farmers }\end{array}$ & 91.0 & 71.0 & 86.0 & 77.0 & 74.0 & 82.0 \\
$\quad$ Sprayers & 7.0 & 11.0 & 9.0 & 17.0 & 5.0 & 11.0 \\
$\quad$ General public & 2.0 & 18.0 & 5.0 & 6.0 & 21.0 & 7.0 \\
& & & & & & \\
Reasons for intended & & & & & & \\
audience & & & & & & \\
Farmers use pesticide & 76.0 & 76.0 & 44.0 & 75.0 & 59.0 & 42.0 \\
The information is & 22.0 & 14.0 & 17.0 & 19.0 & 41.0 & 33.0 \\
$\quad$ relevant to them & & & & & & \\
It was shown by & 2.0 & 3.0 & 4.0 & 2.0 & 0.0 & 2.0 \\
$\quad$ pesticide agents & 0.0 & 0.0 & 30.0 & 4.0 & 0.0 & 23.0 \\
Rice images in poster & 0.0 & 7.0 & 5.0 & 0.0 & 0.0 & 0.0 \\
Don't know & & & & & & \\
\hline
\end{tabular}




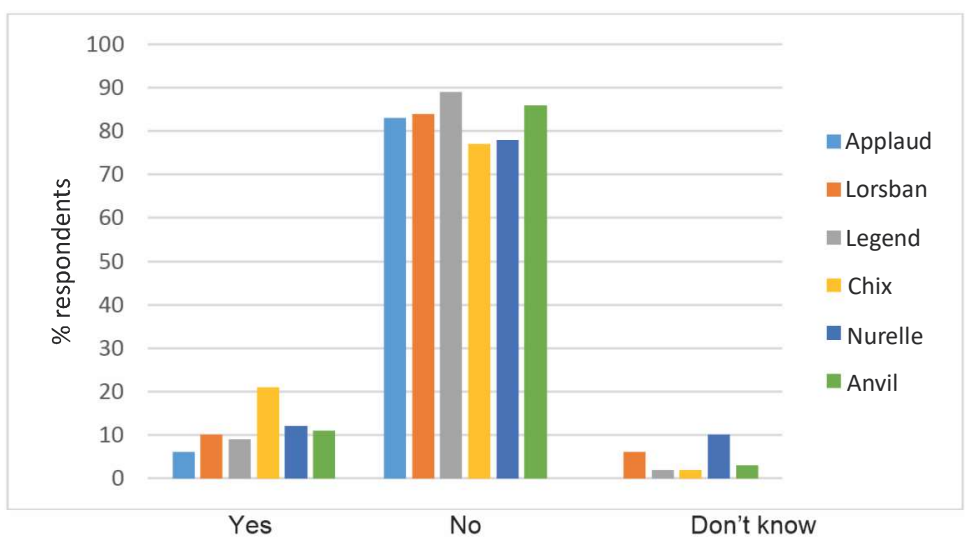

Fig. 3. Distribution of respondents who found something offensive in posters.

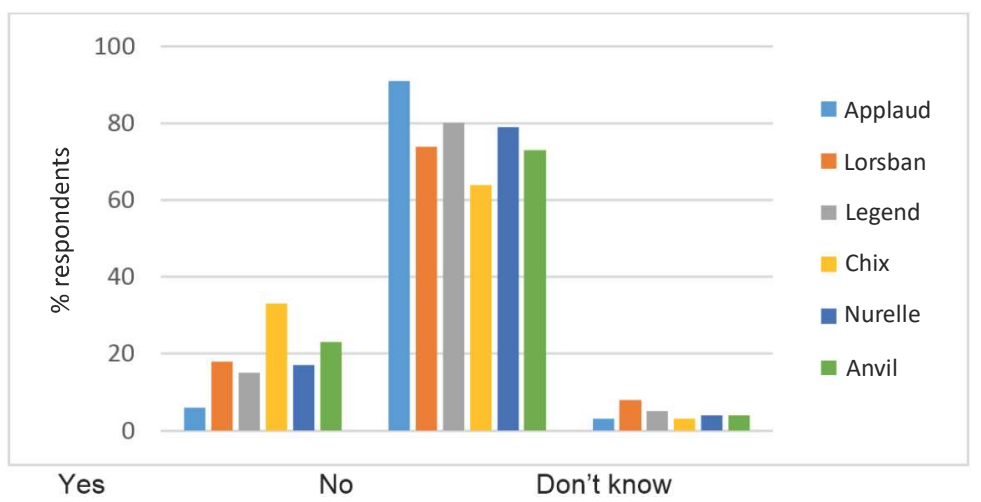

Fig. 4. Distribution of respondents who found something in posters they did not believe to be true.

\section{Focus Group Discussion}

The focus group discussion results seemed to reflect the findings of individual interviews. Most of the FGD participants expressed that they found the posters attractive and that the posters would help solve their pest problems, help them choose good chemicals, and kill insects in the fields. Some participants admitted that posters encouraged them to buy pesticides. Others were even thankful for the poster because it reminded them about what pesticide to use for specific pests. Respondents also agreed with the slogans used in the posters as they thought that the product claims were already tested and proven by professionals which could help them choose the appropriate chemical to control a specific pest.

\section{IMPLICATIONS AND RECOMMENDATIONS}

This study focused on understanding farmers' interpretation of insecticide posters. Focus group discussion results indicated that farmers had knowledge gaps and misconceptions of the posters' message. Farmers thought that the posters encouraged them to use pesticide excessively when that recommendation was not in the posters. It appears that pesticide use has been well entrenched in the minds of farmers that a poster is perceived to be associated with insecticide use. 
In promoting a pesticide and entice farmers to buy it, the results clearly showed that companies can focus on branding, visual images, and text size of outdoor print advertisements such as the poster. These elements in the posters were most attractive to farmers. Moreover, realistic images in the posters can help the audience relate and understand and have confidence to buy the product. The use of animated images in the poster on the other hand, seemed to have negative influence. Text size could also be considered as most of the respondents who belonged to the old age bracket and had visual acuity problems, had difficulty recognizing the small font size used.

The study clearly showed that farmers could easily be influenced to buy and apply pesticides. The main message the posters had to most farmers was reminding them to apply the pesticides. These promotional devices had direct influence on promoting applications but not necessarily appropriate and profitable use of pesticides for pest management. In fact in most cases Asian farmers' insecticide applications have questionable productivity gains (Heong, et al., 2015a). It is now well established that inappropriate use (or misuse) of insecticides tends to induce the development of secondary pests, the brown planthopper, that had become a major threat to rice production in Asia (Heong, et al., 2015). Pesticide misuse, not only can induce pest outbreaks, but it is also a threat to the environment and human health (Heong et al., 2015b). Sublethal doses of certain insecticides are now known to cause bee colony collapse (Raine and Gill, 2015) and neurological diseases, such as Parkinson's and Alzheimer's diseases in humans (Casida et al., 2013).

\section{Suggestions for Further Research}

A future study to systematically assess the credibility of insecticide posters and its influence on pest management decisions of farmers is suggested. In this study the credibility factors of expertise, trustworthiness, and attractiveness need to be explored. Another relevant study evaluating pesticide posters should be done to probe other possible reasons why some farmers misuse pesticides. A content analysis of popular pesticide posters can likewise be undertaken to examine the selling points and emotional appeals used which might create fear associated with misuses and interviews with farmers can be conducted to determine if the appeals used resonate with the intended audience. Results of this study can help IPM and green agriculture advocates to counteract excessive and unnecessary pesticide use.

In development communication studies that include pest management practice as one of the independent variables, the number of pesticide applications, disaggregated by type of pesticide, should be included since this is the gold standard in measuring pest management practice.

\section{ACKNOWLEDGMENT}

We are grateful to Dr. K.L. Heong for bringing to bear his insights in pest management issues in Asian rice in reviewing this paper. 


\section{REFERENCES}

BERTRAND, J. T. 1978. Communication pretesting. Chicago: University of Chicago Community and Family Study Center.

CASIDA, J.E. and K.A. DURKIN. 2013. Neuroactive insecticides: Targets, selectivity, resistance and secondary effects. Annual Review of Entomology 58,99117.

CHENG, J. and K.L. HEONG, 2010. Pesticide tsunami- a root cause of rice planthopper problemsin Asia. Retrieved November 5, 2010, from:http:/ / ricehoppers.net/

DIAZ, R.2002. Information sources and knowledge, beliefs and practices in nutrient management among rice farmers in Leyte. Unpublished BS Development Communication thesis, Visayas State University, Baybay, Leyte, Philippines.

ESCALADA, M. M., K.L. HEONG, N.H. HUAN and H.V. CHIEN. 2009. Changes in rice farmers' pest management belief and practices in Vietnam: An analytical review of survey data from 1992 to 2007. In K. Heong \& B. Hardy (Eds.), Planthoppers: New threats to the sustainability of intensive rice production system in Asia, (pp. 447-456). Los Baños (Philippines): International Rice Research Institute.

ESCALADA, M.M., K.L. HEONG, N.H. HUAN, and V. MAI. 1999. Communication and behavioral change in rice farmers' pest management: The case of using mass media in Vietnam. Journal of Applied Communication, 83(1), 7-26.

FAO, (2000). Pesticides. Retrieved November 8, 2010, from: http://www.communityipm.org/docs/Tea_Eco-Guide/12_Pesticides.PDF

GREENPEACE. 2008. Agrochemical use in the Philippines and its consequences on the environment. Retrieved November 11, 2010 , from: www.greenpeace.to/.../GPSEA_agrochemical-use-in-the-philip.pdf

HEONG, K.L., J.A. CHENG, and M.M. ESCALADA. a (Eds.) Rice Planthoppers: Ecology, Management, Socio Economics and Policy, Zhejiang University Press, Hangzhou and Springer Science+Business Media Dordrecht.

HEONG, KL, L. WONG and J.H. DELOS REYES. b 2015. . Chapter 3. In Heong, K.L., J.A. Cheng \& M.M. Escalada. (Eds.) Rice Planthoppers: Ecology, Management, Socio Economics and Policy (pp. 69 - 80). Hangzhou: Zhejiang University Press and Springer Science+Business Media Dordrecht.

HeONG, K.L., M.M. ESCALADA, H.V. CHIEN, and J.H. DELOS REYES. c . 2015. Chapter 10. In Heong, K.L., J.A. Cheng \& M.M. Escalada. (Eds.) Rice Planthoppers: Ecology, Management, Socio Economics and Policy (pp. 181-192). Hangzhou: Zhejiang University Press and Springer Science+Business Media Dordrecht.

KINCHELOE, J.L. and R.A. HORN . 2006. The Praeger handbook of education and psychology. Sta. Barbara, CA (USA): Praeger Publishers.

LI, S., Y. GUO, G. HU, and D. LIANG. 1997. Pest management practices of rice farmers in Hunan, China. In M.M. Escalada \& K.L. Heong (Eds.), Pest management of rice farmers in Asia (pp. 53-62). Los Baños (Philippines): International Rice Research Institute.

MANGAN, J. and M. MANGAN. 1998. A comparison of two IPM training strategies in China. Agriculture and Human Values, 15(3) 209-221. 
Interpretation of Insecticide Posters by Rice Farmers

RAINE, N.E. and GILL, R.J. 2015. Tasteless pesticides affect bees in the field. Nature.

ROLA, A. C. and P.L. PINGALI. 1993. Pesticides, rice productivity and farmers' health: An economic assessment. Los Baños (Philippines): International Rice Research Institute.

UPANISAKORN, A. 1997. Farmer participatory research in rice pest management: Its impact on farmers' decision making and arthropod diversity in Chainat, Thailand. Unpublished MS thesis, Kasetsart University, Thailand. 